\title{
Investigation of Lifetime-Limiting Defects After High-Temperature Phosphorus Diffusion in High-Iron-Content Multicrystalline Silicon
}

\author{
David P. Fenning, Annika S. Zuschlag, Jasmin Hofstetter, Alexander Frey, Mariana I. Bertoni, Giso Hahn,
} and Tonio Buonassisi

\begin{abstract}
Phosphorus diffusion gettering of multicrystalline silicon solar cell materials generally fails to produce material with minority-carrier lifetimes that approach that of gettered monocrystalline wafers, due largely to higher levels of contamination with metal impurities and a higher density of structural defects. Higher gettering temperatures should speed the dissolution of precipitated metals by increasing their diffusivity and solubility in the bulk, potentially allowing for improved gettering. In this paper, we investigate the impact of gettering at higher temperatures on low-purity multicrystalline samples. To analyze the gettering response, we measure the spatially resolved lifetime and interstitial iron concentration by microwave photoconductance decay and photoluminescence imaging, and the structural defect density by Sopori etching and large-area automated quantification. Higher temperature phosphorus diffusion gettering is seen to improve metal-limited multicrystalline materials dramatically, especially in areas of low etch pit density. In areas of high as-grown dislocation density in the multicrystalline materials, it appears that higher temperature phosphorus diffusion gettering reduces the etch pit density, but leaves higher local concentrations of interstitial iron, which degrade lifetime.
\end{abstract}

Index Terms-Dislocation density, iron gettering, minoritycarrier lifetime, phosphorus diffusion, silicon solar cells.

\section{INTRODUCTION}

$\mathbf{P}$ HOSPHORUS diffusion gettering (PDG) of metal impurities is a kinetically limited process in multicrystalline

D. P. Fenning is with the Massachusetts Institute of Technology, Cambridge, MA 02139 USA, and also with the Department of Nanoengineering, University of California San Diego, La Jolla, CA 92093 USA (e-mail: dfenning@ alum.mit.edu).

A. S. Zuschlag, A. Frey, and G. Hahn are with the Department of Physics, University of Konstanz, Konstanz 78457, Germany (e-mail: annika.zuschlag@unikonstanz.de; alexander.frey@uni-konstanz.de; giso.hahn@uni-konstanz.de).

J. Hofstetter and T. Buonassisi are with the Massachusetts Institute of Technology, Cambridge, MA 02139 USA (e-mail: jhofstet@mit.edu; buonassisi@ mit.edu).

M. I. Bertoni is with the Department of Electrical, Computer and Energy Engineering, Arizona State University, Tempe, AZ 85287 USA (e-mail: bertoni@ asu.edu). silicon (mc-Si) because the high contamination levels in mc$\mathrm{Si}$ generally exceed the solid solubility at process temperatures [1], [2]. While there are many demands on a phosphorus diffusion profile designed for a high-performance emitter [3], such as achieving a low emitter saturation current, high $V_{\mathrm{oc}}$, and good blue response, iron typically dominates the minoritycharge carrier lifetime in the bulk in p-type mc-Si [4]. Current PDG of contaminated mc-Si solar cell materials generally fails to remove significant amounts of precipitated iron [5] and produces material with minority-carrier lifetimes that do not approach that of phosphorus-diffused monocrystalline wafers [6].

Because of the Arrhenius relationship of impurity diffusivity and solubility, higher gettering temperatures should markedly accelerate dissolution of precipitated metals [7]. Recently, confirmation of the improved gettering of precipitated metals at higher temperature has been found by synchrotron-based X-ray fluorescence microscopy [8], [9]. However, in the literature, mixed lifetime results have been seen when performing PDG at higher temperatures. For example, Ballif et al. [10] saw lifetime degradation using gettering temperatures above about $875^{\circ} \mathrm{C}$ in material from the very bottom of a p-type cast multi ingot, suggesting that a high dislocation density and dissolving precipitates could be responsible for the increased recombination activity. An order of magnitude higher interstitial iron concentration was seen after diffusion at $950^{\circ} \mathrm{C}$ compared with a $830^{\circ} \mathrm{C}$ diffusion. Alternatively, Möller et al. [11]-[13] and Macdonald and Cuevas [14] point to the impact of oxygen precipitates, dislocation decoration with metals, and a rise in dislocation density during annealing to account for lower lifetimes after higher temperature processing. Franke [15] also found a higher dislocation density with higher temperature diffusions in Czochralski $(\mathrm{Cz})$ material. On the other hand, Peters et al. [16] showed that millisecond lifetimes could be maintained in float-zone silicon, even with fast ramping rates of roughly $100 \mathrm{~K} / \mathrm{s}$ using rapid thermal processing, indicating that the existing defects in multicrystalline and $\mathrm{Cz}$ materials cause degradation. In this paper, we investigate the impact and limitations of gettering at higher temperatures in high-iron mc$\mathrm{Si}$, applying detailed microcharacterization to assess potential lifetime-limiting defects, specifically interstitial iron and dislocations.

\section{Methods}

Seven adjacent wafers along the ingot height (sister wafers) were selected from the top $(\approx 90 \%$ ingot height $)$ of a 
TABLE I

Square-Root-Weighted Harmonic Mean Lifetime and AREa Fraction With Etch Pit Density $>10^{6} \mathrm{CM}^{-2}$

\begin{tabular}{cccccccc}
\hline & As-Grown & $820^{\circ} \mathrm{C}$ & $870^{\circ} \mathrm{C}$ & $920^{\circ} \mathrm{C}$ & $920^{\circ} \mathrm{CN}_{2}+820^{\circ} \mathrm{C}$ & $920^{\circ} \mathrm{C}+820^{\circ} \mathrm{C}$ & $920^{\circ} \mathrm{C}+\mathrm{LTA}$ \\
\hline Sheet Resistance $(\Omega / \mathrm{sq})$. & & $62.6 \pm 1.6$ & $23.2 \pm 0.6$ & $10.6 \pm 0.2$ & $67.6 \pm 1.7$ & $60.3 \pm 1.3$ & $11.5 \pm 0.1$ \\
Post-PDG Avg. Lifetime $(\mu \mathrm{s})$ & & 9.6 & 17.0 & 14.2 & 14.7 & 23.4 & 22.2 \\
Area Fraction with $>10^{6} \mathrm{~cm}^{-2} \mathrm{EPD}$ & 0.31 & 0.24 & 0.18 & 0.12 & 0.26 & 0.14 & 0.10 \\
Reduction from As-Grown & - & $23 \%$ & $42 \%$ & $61 \%$ & $16 \%$ & $55 \%$ & $68 \%$ \\
\hline
\end{tabular}
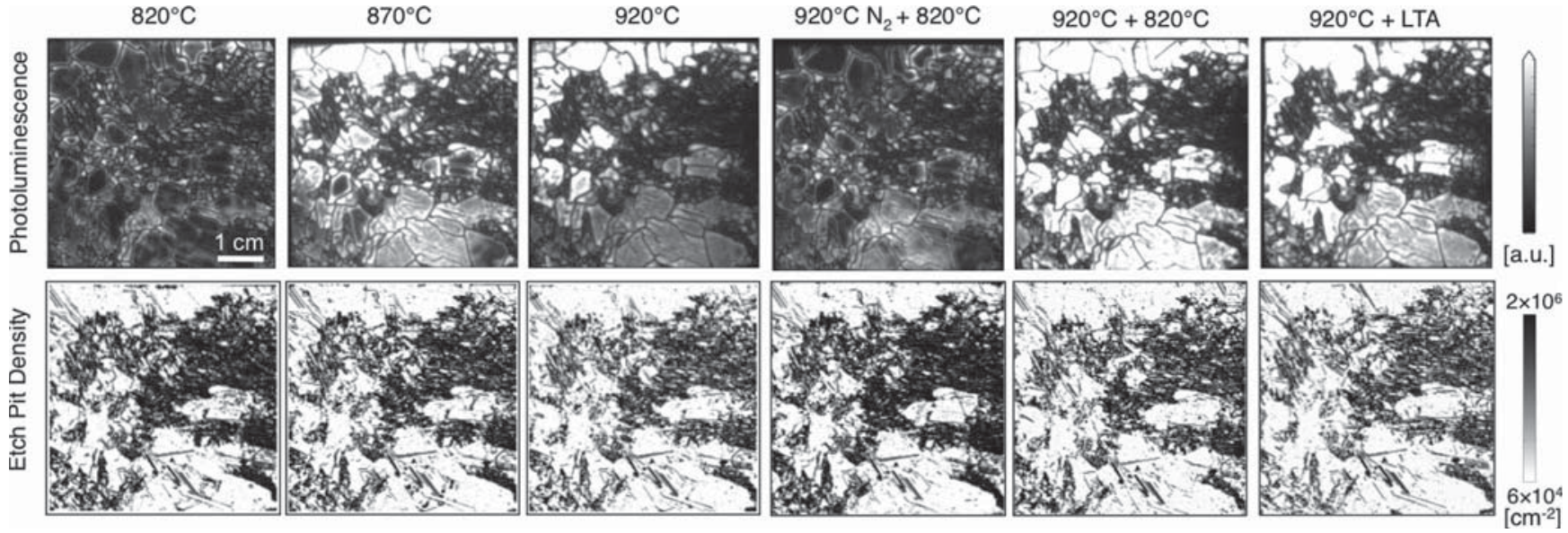

Fig. 1. Photoluminescence images are shown in the first row as a function of sample gettering conditions. Samples are $\approx 5 \times 5 \mathrm{~cm}^{2}$. Quantified EPD maps after a 30-s Sopori etch are shown in the second row.

boron-doped mc-Si ingot intentionally contaminated with 20 ppma Fe. Details on the metal concentration in this ingot can be found in [17]. The total Fe concentration in these wafers is about $10^{15}$ atoms $/ \mathrm{cm}^{3}$. Such high iron concentrations can be found readily in the edge regions of cast multicrystalline ingots [18] that do not use a high-purity crucible and coating [19].

After saw-damage etching and cleaning, the as-grown density of structural defects was measured by performing a 30-s Sopori etch [20] on one of the wafers followed by optical scanning using a flatbed scanner and automated etch pit counting [21].

Single-step phosphorus diffusions were carried out on three sister wafers at different gettering temperatures, namely $820^{\circ} \mathrm{C}$, $870^{\circ} \mathrm{C}$, and $920^{\circ} \mathrm{C}$. Three additional sister samples had twostep gettering processes: one was annealed at $920^{\circ} \mathrm{C}$ in nitrogen prior to $820^{\circ} \mathrm{C} \mathrm{POCl}_{3}$ deposition and gettering (designated $920^{\circ} \mathrm{C} \mathrm{N}_{2}+820^{\circ} \mathrm{C}$ ), the second was gettered at $920^{\circ} \mathrm{C}$ followed by cooling of several ${ }^{\circ} \mathrm{C} / \mathrm{min}$ within the furnace to $600^{\circ} \mathrm{C}$ and a low-temperature anneal at $600^{\circ} \mathrm{C}$ for $60 \mathrm{~min}\left(920^{\circ} \mathrm{C}+\mathrm{LTA}\right)$, while the third was P-diffused at $920^{\circ} \mathrm{C}$, etched off, and $\mathrm{P}$ diffused again at $820^{\circ} \mathrm{C}\left(920^{\circ} \mathrm{C}+820^{\circ} \mathrm{C}\right)$. The duration of each $\mathrm{P}$-diffusion step (deposition + drive-in) was about an hour in each case, except the $920^{\circ} \mathrm{C} \mathrm{N}_{2}+820^{\circ} \mathrm{C}$ where the P-diffusion was shorter $(\approx 45 \mathrm{~min})$. The resulting emitter sheet resistances are listed in Table I.

After the gettering steps were completed, the emitter was etched off in preparation for photoluminescence imaging (PLI) and microwave photoconductance decay ( $\mu$-PCD) lifetime measurements. Finally, defect etching and full-area etch pit density (EPD) quantification was performed on all gettered samples.

\section{RESULTS}

\section{A. Lifetime Impact of One- and Two-Step High-Temperature Gettering}

Photoluminescence images of all gettered samples are shown in the top row of Fig. 1 with all images scaled to the same limits. The sample surfaces were passivated with quinhydrone methanol [22] for the measurement.

One can see immediately from the PLI of the $820^{\circ} \mathrm{C}, 870^{\circ} \mathrm{C}$, and $920^{\circ} \mathrm{C}$ single-step gettering samples shown on the top left that the band-to-band photoluminescence signal, and, by proxy, the bulk lifetime, is strongly influenced by the peak phosphorus diffusion temperature, as reported previously [9]. The $870^{\circ} \mathrm{C}$ and $920^{\circ} \mathrm{C}$ processes result in significantly enhanced signal across much of the sample area. This observation is supported by the PLI of the two-step processes as well. The two samples gettered with their phosphorus diffusion conducted at $920^{\circ} \mathrm{C}$, on the far right of Fig. 1, show strongly improved lifetime over the $920^{\circ} \mathrm{C} \mathrm{N}_{2}+820^{\circ} \mathrm{C}$ sample phosphorus diffused at $820^{\circ} \mathrm{C}$.

The local response to higher gettering temperatures within each sample, however, is seen to be strongly dependent on the local structural defect density. Comparing the PLI in Fig. 1 with the EPD maps below reveals that regions of low structural defect density show excellent response to the higher temperature gettering step. However, the heavily dislocated region in the upper right of the samples, for example, degrades somewhat during the single-step $920^{\circ} \mathrm{C}$ process. The dislocation density is known to play a crucial role in determining the gettering response with improved gettering often seen in areas of low dislocation density [4], [23]-[25]. 


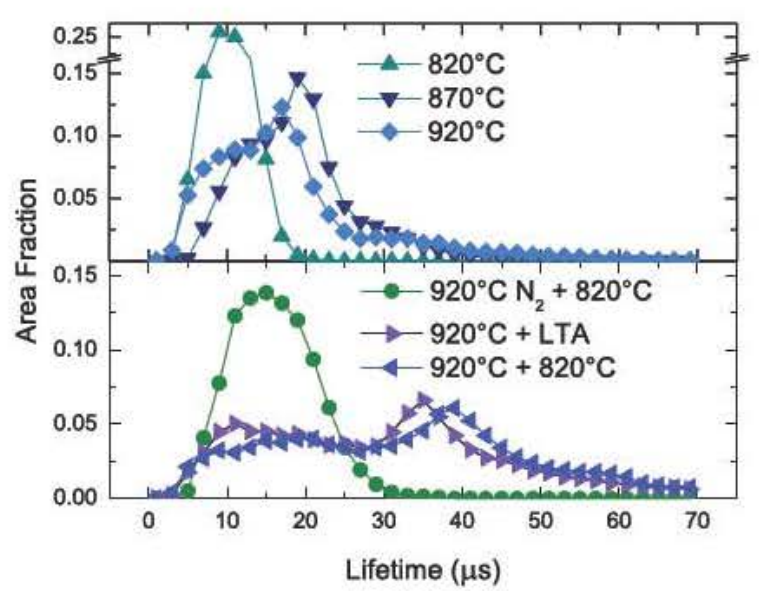

Fig. 2. Lifetime histograms from $\mu$-PCD measurements after gettering. A high-lifetime tail develops in the lifetime distribution by moving to higher phosphorus diffusion temperatures in single-step processes, but by $920^{\circ} \mathrm{C}$, this lifetime improvement begins to be offset by degradation in other areas of the sample. The highest lifetimes come from two-step processes where a $920^{\circ} \mathrm{C}$ P-diffusion step is followed by a lower temperature P-diffusion step or a lowtemperature anneal.

Adding a lower temperature step after a $920^{\circ} \mathrm{C}$ phosphorus diffusion improves lifetime significantly. Comparing the PLI of the single-step $920^{\circ} \mathrm{C}$ sample with the two rightmost samples phosphorus diffused at $920^{\circ} \mathrm{C}$ but with lower temperature secondary steps reveals that essentially all areas respond positively to a high-temperature phosphorus diffusion followed by a lower temperature process.

Quantitative spatially resolved lifetime measurements on all samples were obtained before PLI by $\mu$-PCD lifetime measurements with the samples passivated with iodine-ethanol. Spatially resolved lifetimes in the as-grown sample were below $2 \mu \mathrm{s}$ (not shown). The lifetime histograms from the spatially resolved measurement for the gettered samples are shown in Fig. 2, and the square-root-weighted harmonic mean lifetime for each sample, calculated as $\frac{1}{\sqrt{\tau_{a v}}}=\frac{1}{n} \Sigma \frac{1}{\sqrt{\tau_{i}}}$, which is proportional to the harmonic mean minority-carrier diffusion length and a strong predictor of cell performance [26]-[28], is reported in Table I.

After gettering at the baseline temperature of $820^{\circ} \mathrm{C}$, the lifetime is tightly distributed with a calculated average of $9.6 \mu \mathrm{s}$, as seen in Fig. 2 (upward triangles) and in Table I. The $920^{\circ} \mathrm{C} \mathrm{N}_{2}+820^{\circ} \mathrm{C}$ improves the average lifetime to $14.7 \mu$ s, while maintaining a relatively tight distribution (circles). By increasing the phosphorus diffusion temperature to $870^{\circ} \mathrm{C}$, the majority of the lifetime distribution shifts to higher values with a high-lifetime tail developing (downward triangles). Compared with the $820^{\circ} \mathrm{C}$ sample, the average lifetime of the $870^{\circ} \mathrm{C}$ sample almost doubles to $17.0 \mu$ s. From comparison with the PLI in Fig. 1, it is clear that this high-lifetime tail comes from the large-grain areas of low dislocation density. Moving to a $920^{\circ} \mathrm{C}$ diffusion produces primarily an increase in variation in lifetime across the sample (diamonds). The high-lifetime tail is extended with values reaching $70 \mu$ s, but a significant fraction of the wafer degrades with respect to the $870^{\circ} \mathrm{C}$ lifetime distribution, falling below $15 \mu \mathrm{s}$. In comparison with the $870^{\circ} \mathrm{C}$ PDG, the

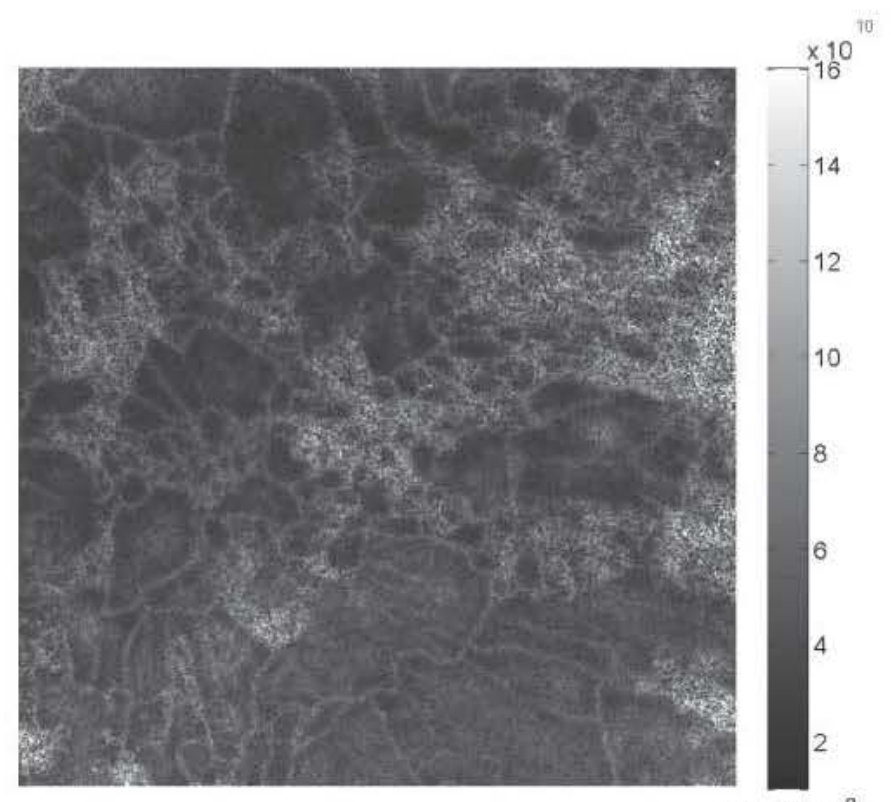

$\left[\mathrm{Fe}_{i}\right]\left(\mathrm{cm}^{-3}\right)$

Fig. 3. Iron imaging of the $920^{\circ} \mathrm{C}+820^{\circ} \mathrm{C}$ sample by photoconductancecalibrated photoluminescence reveals high local interstitial iron concentration remaining after gettering in the vicinity of structural defects.

square-root-weighted harmonic root mean lifetime after $920^{\circ} \mathrm{C}$ PDG falls to $14.2 \mu \mathrm{s}$.

Significant increases in the lifetime distribution are seen by adding a lower temperature step after a $920^{\circ} \mathrm{C}$ PDG. Both the addition of a low-temperature anneal at $600^{\circ} \mathrm{C}(22.2 \mu$ s average $)$ or an etched off and $\mathrm{PDG}$ at $820^{\circ} \mathrm{C}(23.4 \mu$ s average $)$ produce superior lifetime response.

\section{B. Interstitial Iron Imaging After Gettering}

To better understand the effects of the two-step gettering processes, interstitial iron imaging was performed at low-level injection by the iron-boron pair dissociation method [29] on the highest lifetime sample, the $920^{\circ} \mathrm{C}+820^{\circ} \mathrm{C}$ sample. Only in this sample did the injection level under laser illumination easily surpass the onset of trapping at about $\Delta n=4 \times 10^{14} \mathrm{~cm}^{-3}$, allowing for an appropriate calibration of the PLI signal in the injection regime above trapping following the approach taken by Herlufsen et al. [30]. The error in the calibration is estimated to be less than $20 \%$. Iron imaging of the other samples were not possible to calibrate but support the results described next qualitatively.

The calibrated interstitial iron concentration measurement, shown in Fig. 3, provides some insight into the defects underlying the observed lifetime distributions after these alternative gettering processes. By comparison with Fig. 1, it appears that the interstitial iron concentration is especially high near most all regions containing structural defects, both grain boundaries and dislocation clusters, contributing to the low local lifetimes. On the other hand, we can see that the intragranular regions of the larger grains show low interstitial iron concentrations $\left(2-3 \times 10^{10} \mathrm{~cm}^{-3}\right)$ and consequently higher PL signal. The 


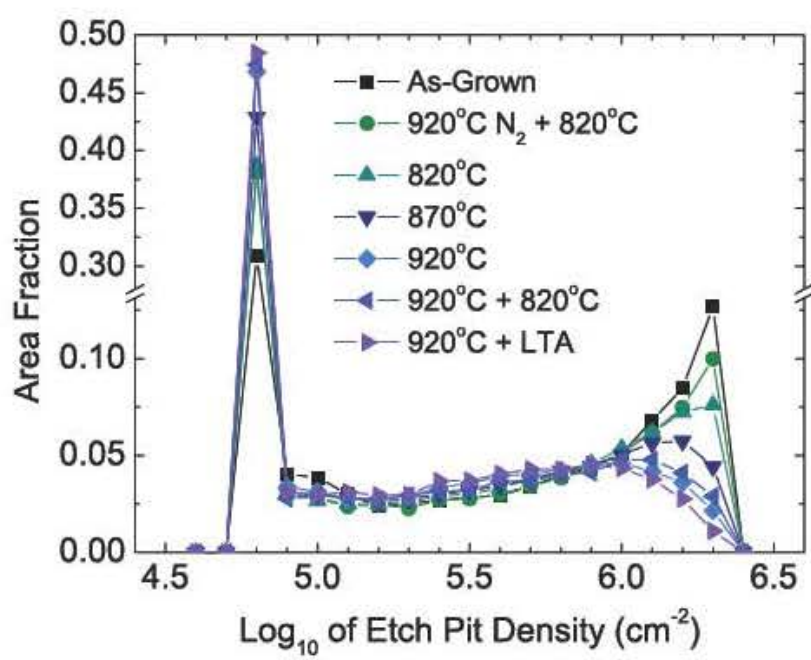

Fig. 4. Histograms of the EPD shown on a log scale. The as-grown distribution is bimodal, with a large number of pixels at the lower limit of the measurement in the large grain, largely dislocation-free areas, but a significant fraction of the wafer contains a high density of etch pits $\left(>10^{6} \mathrm{~cm}^{2}\right)$. Gettering is seen to reduce the frequency of the highest-density areas, while also increasing the fraction of low-density areas. The reduction is monotonic with the phosphorus diffusion temperatures of $820^{\circ} \mathrm{C}, 870^{\circ} \mathrm{C}$, and $920^{\circ} \mathrm{C}$.

implications of this heterogeneous interstitial iron distribution will be discussed below.

\section{Etch Pit Density Reduction During P-Diffusion Gettering}

It is interesting to note from the scanner etch pit images of Fig. 1 that the EPD decreases as the PDG temperature increases from $820^{\circ} \mathrm{C}$ to $920^{\circ} \mathrm{C}$. The distributions of the EPD in the samples are extracted from the scanner etch pit images of Fig. 1 and plotted in Fig. 4. The upper bound on the observable EPD was limited to $\approx 3 \times 10^{6} \mathrm{~cm}^{2}$ by the size of the etch pits. The asgrown, $820^{\circ} \mathrm{C}, 870^{\circ} \mathrm{C}, 920^{\circ} \mathrm{C}$, and $920^{\circ} \mathrm{CN}_{2}+820^{\circ} \mathrm{C}$ samples were etched at the same time to minimize variation. Scanner images were calibrated to a $2 \times 1 \mathrm{~cm}^{2}$ optical micrograph of one of the samples. The $920^{\circ} \mathrm{C}+820^{\circ} \mathrm{C}$ and $920^{\circ} \mathrm{C}+\mathrm{LTA}$ samples were processed later to add to the dataset and were etched together. A new calibration for these two samples resulted in insignificant differences in the etch pit distribution compared with the calibration used for the other samples, and so the original calibration was used for all samples in Fig. 4. Because all samples were etched prior to diffusion and then again to remove the emitter, the surfaces were effectively chemically polished, reducing false positives in defect detection [21].

The as-grown distribution is largely bimodal, with a significant fraction of the wafer containing $<10^{5} \mathrm{~cm}^{-2}$ and another significant portion containing $>10^{6} \mathrm{~cm}^{-2}$. Gettering at $820^{\circ} \mathrm{C}$ increases the frequency below $10^{5} \mathrm{~cm}^{-2}$ and decreases the frequency of areas containing etch pit densities above $>10^{6} \mathrm{~cm}^{-2}$. The EPD distribution of the $920^{\circ} \mathrm{C} \mathrm{N}_{2}+820^{\circ} \mathrm{C}$ sample is similar to the $820^{\circ} \mathrm{C}$ standard PDG sample. Higher temperature PDG at $870^{\circ} \mathrm{C}$ and $920^{\circ} \mathrm{C}$ monotonically reduces the frequency of the most-heavily pitted areas while increasing the area fraction with few or no pits.
The area fraction in each sample with EPD $>10^{6} \mathrm{~cm}^{-2}$ is reported in Table I, along with a calculation of the percent reduction in area with high EPD with respect to the as-grown sample. The decrease in high-density $\left(>10^{6} \mathrm{~cm}^{-2}\right)$ area fraction in the samples with phosphorus diffusion at $920^{\circ} \mathrm{C}$ sample is dramatic, with $55 \%, 61 \%$, and $68 \%$ reduction with respect to the as-grown sample for the $920^{\circ} \mathrm{C}+820^{\circ} \mathrm{C}, 920^{\circ} \mathrm{C}$, and $920^{\circ} \mathrm{C}+$ LTA samples, respectively.

To further investigate the wafer-level EPD, $20 \times$ optical micrographs were taken in the region from the center right of the wafers that showed areas of both high and low EPD. Fig. 5 shows a portion of the micrographs, with dark areas corresponding to areas of high EPD. The scale bar is $1 \mathrm{~mm}$. Inspection of the images reveals a significant reduction in EPD for all gettered samples with respect to the as-grown sample (which is homogeneously a slightly darker color because of larger surface roughness).

In agreement with the results from the scanner images, the most notable reductions in EPD occur for the higher temperature phosphorus diffusions, including the $870^{\circ} \mathrm{C}$ sample shown in Fig. 5(c), but especially for the samples with phosphorus diffusions occurring at $920^{\circ} \mathrm{C}$, seen in Fig. 5(d), (f), and (g). Comparing the micrographs of the samples that received a $920^{\circ} \mathrm{C}$ phosphorus diffusion to the as-grown sample reveals a striking decrease in EPD. Importantly, the etch pit distribution in the $920^{\circ} \mathrm{CN}_{2}+820^{\circ} \mathrm{C}$ sample seen in Fig. 5(e) appears much more similar to Fig. 5 (b) the $820^{\circ} \mathrm{C}$ sample than Fig. 5 (d) the $920^{\circ} \mathrm{C}$.

\section{DISCUSSION}

\section{A. Remaining Spatial Nonuniformities in Lifetime Response: Interactions Between Dislocations and Metal Impurities}

In a previous study on additional samples from the same ingots and ingot heights, the higher $870^{\circ} \mathrm{C}$ and $920^{\circ} \mathrm{C} \mathrm{P}$-diffusion temperatures were found to significantly reduce the size of ironrich precipitates compared with the baseline $820^{\circ} \mathrm{C}$ phosphorus diffusion temperatures [9]. At higher phosphorus gettering temperatures, more precipitated iron is dissolved and becomes getterable interstitials.

It appears from Fig. 3 that even after $920^{\circ} \mathrm{C}$ phosphorus diffusion followed by an $820^{\circ} \mathrm{C}$ diffusion process, there remains a significant amount of iron decorating the structural defects that serves as sources for interstitial injection into the bulk. Some of this iron remains interstitial at the end of the process, having diffused from the structural defects into the surrounding region during processing [31]. The high structural defect density and high interstitial iron concentration lead to low lifetimes after gettering in such regions of the wafer.

While quantitative results were not achieved in iron imaging of the $920^{\circ} \mathrm{C}$ sample because of trapping effects (not shown), a similarly high local interstitial iron concentration appears to be the cause for degradation in regions rich with structural defects, resulting in the lower average lifetime compared with the $870^{\circ} \mathrm{C}$ sample despite a much higher lifetime tail.

Adding a lower temperature step after the $920^{\circ} \mathrm{C}$ phosphorus diffusion appears crucial to ensuring that this mobile, but electronically detrimental, interstitial population is reduced to 
(a)

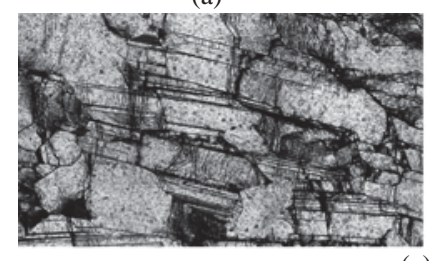

(e)

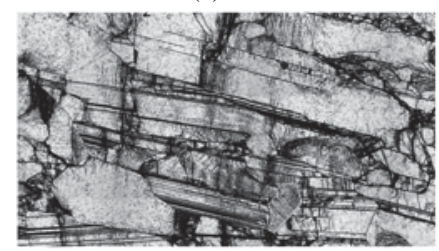

(b)

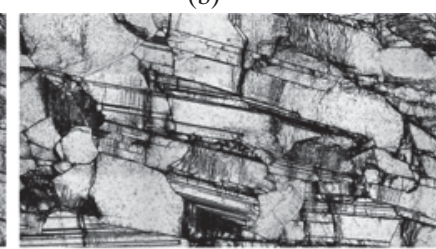

(f) (c)

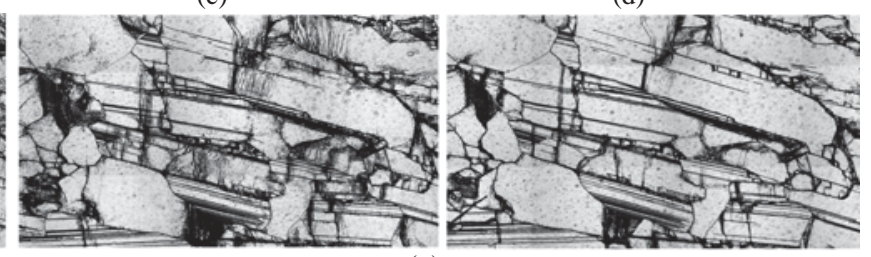

(g)
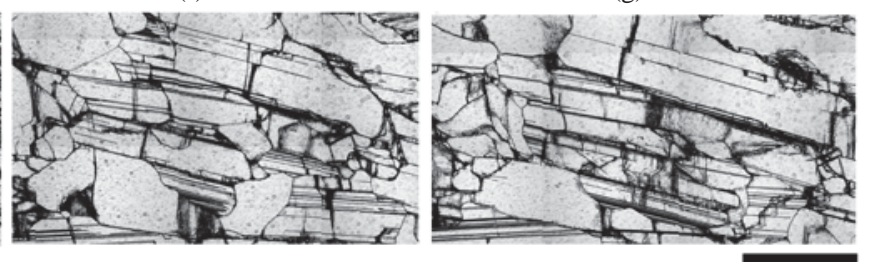

Fig. 5. Optical micrographs of the EPD show a strong correlation with phosphorus diffusion temperature. (a) As-grown. (b) $820^{\circ} \mathrm{C}$. (c) $870^{\circ} \mathrm{C}$. (d) $920^{\circ} \mathrm{C}$. (e) $920^{\circ} \mathrm{C} \mathrm{N}_{2}+820^{\circ} \mathrm{C}$. (f) $920^{\circ} \mathrm{C}+$ LTA. (g) $920^{\circ} \mathrm{C}+820^{\circ} \mathrm{C}$. Notably, the $920^{\circ} \mathrm{C} \mathrm{N}_{2}+820^{\circ} \mathrm{C}$ appears more similar to the $820^{\circ} \mathrm{C}$ sample than the samples phosphorus-diffused at $920^{\circ} \mathrm{C}$. Scale bar is $1 \mathrm{~mm}$.

moderate levels before the end of processing, allowing for the highest lifetimes to be achieved in the two-step $920^{\circ} \mathrm{C}$ PDG processes. Coupling a higher temperature gettering with a lower temperature step is critical, as precipitates remain sources for interstitial injection into the bulk throughout the gettering process and even during firing, the last high-temperature step of the solar cell process.

\section{B. When to Apply Higher Gettering Temperatures}

Overall, the mixed performance even within the same material in response to higher temperature processing demands caution. During gettering, the extraction of interstitial iron is effective in intragranular regions with low structural defect density. Thus, in iron-contaminated materials, areas of lower structural defect density that show poor lifetimes in the as-grown material may lead to the highest gettered lifetimes: a reversal is seen in the lifetime contrast across structural defects, save immediately at the defect itself where recombination remains high. This appears to be the case with the heavily Fe-contaminated samples examined here, where one observes that the low as-grown lifetime intragranular regions become the highest gettered lifetime regions after a standard diffusion (cf., lifetime maps in [9] for full comparison). These regions are largely devoid of dislocations or other structural defects that impede gettering [32], demonstrated by dislocation etching and imaging seen in Fig. 1. The lifetime contrast reversal seen here at structural defects in this iron-contaminated mc-Si does not occur, for example, in a study of metal gettering by Bentzen et al. in higher quality starting materials [33]. There, the poorest as-grown regions remained the worst areas after gettering.

The presence of higher lifetime denuded zones around structural defects in the as-grown material (see, e.g., [34]) is a potential metric to determine whether higher temperature diffusion will be beneficial. When metals are the principal lifetimelimiting defect in as-grown materials, nucleation and precipitate growth during cooldown from crystallization leads to internal gettering near structural defects, generating higher lifetimes in areas rich with metal impurities and structural defects [29], [35]. During gettering, these precipitates act as semi-infinite sources for metal point defects, poisoning the local area [31]. In contrast, the worst as-grown areas are dominated by high metal pointdefect concentrations, because of a paucity of available nucleation sites. In summary, when lifetime contrast between areas with structural defects and the intragranular bulk reverses after standard gettering, higher temperature phosphorus diffusion may prove useful because the material is likely metal limited.

\section{Possible Mechanisms for Change in Etch Pit Density}

In the following, it is important to consider whether the EPD corresponds well to the dislocation density. EPD reduction at these relatively low temperatures (below $1000^{\circ} \mathrm{C}$ ) has been observed before by Choi et al. [36] during annealing of mc-Si blocks in the presence of a gettering layer, but here we use standard-thickness wafers.

The first obvious explanation for a change in EPD is that the effect of the defect etch changes with metal-precipitate decoration, perhaps via a Fermi energy pinning effect. It is also possible that phosphorus pipe-diffusion along dislocations during the annealing influenced defect-etching by altering the local Fermi level. However, these hypotheses are not easy to reconcile with the observation that regions of high EPD remain in all samples. Presumably, if some processing variables were to affect dislocation etching, it would affect all uniformly, which is not our observation. Choi et al. [36] also found that the EPD measured for a Secco etch chemistry was the same within experimental error as that found for a Sopori etch chemistry, despite the different etch mechanisms and different energy levels in solution with respect to the Fermi level at the surface.

Furthermore, the sister samples are not perfect controlsthe crystal structure changes slightly between each sampleand so care should be taken in interpreting the differences in EPD. The samples order from bottom to top in the ingot was $920^{\circ} \mathrm{C}+\mathrm{LTA}$, as-grown, $820^{\circ} \mathrm{C}, 870^{\circ} \mathrm{C}, 920^{\circ} \mathrm{C}, 920^{\circ} \mathrm{C} \mathrm{N}_{2}+$ $820^{\circ} \mathrm{C}$, and $920^{\circ} \mathrm{C}+820^{\circ} \mathrm{C}$. The fact that the EPD reduction 
in the $920^{\circ} \mathrm{C} \mathrm{N}_{2}+820^{\circ} \mathrm{C}$ sample does not continue the trends seen when moving up the ingot, but instead closely resembles the $820^{\circ} \mathrm{C}$ sample (see Fig. 4), suggests that an overall trend along the ingot height such as metal contamination level cannot explain the differences in EPD distributions after gettering. Likewise, all samples with a phosphorus diffusion at $920^{\circ} \mathrm{C}$ (the $920^{\circ} \mathrm{C}+\mathrm{LTA}, 920^{\circ} \mathrm{C}$, and $920^{\circ} \mathrm{C}+820^{\circ} \mathrm{C}$ samples) show similar EPD histograms (see Fig. 4) and optical micrographs (see Fig. 5). Apparently, it is the temperature of phosphorus diffusion, rather than the annealing temperature that drives the EPD reduction.

For completeness, we should consider possible mechanisms of long-range dislocation motion that could explain the differences in EPD. Large differences are seen in the etch pit structures between the samples, beyond the simple reduction in number of etch pits (see Fig. 5). Typically, it is considered that homologous temperatures $\left(\mathrm{T} / \mathrm{T}_{\text {melting }}\right)$ of 0.8 are required for dislocation climb to occur in silicon, and polygonization and dislocation recovery above these temperatures has been observed in mc-Si [37]. Given that we are operating well below even $1000{ }^{\circ} \mathrm{C}$, the significant etch pit redistribution here at phosphorus diffusion temperatures $\left(0.58<T / T_{m}<0.65\right)$ is surprising. Speculative mechanisms for the significant changes in the etch pit distribution include:

1) Dislocation motion enhanced by the nonequilibrium injection of Si point defects during phosphorus diffusion. As mentioned previously, large EPD reduction was observed in thick slabs $(5 \mathrm{~mm})$ of mc-Si during phosphorus diffusion by Choi et al. [36], indicating that some other mechanism is active other than, or in addition to, intrinsic point defects to enhance the apparent dislocation motion.

2) A possible reversal of the typical solute-drag effect of dislocations as postulated in [36]. Normally, impurity atoms in solution decorate the dislocation because of the energetically favorable position in the strain field. Dislocation motion is generally slowed by the drag imposed by these solute atoms. However, if during phosphorus diffusion the segregation effect of the gettering layer produces a strong driving force for a net unidirectional flux of impurities to the surface layer, then the impurity atoms collectively may impose a net directional "drag" force act on the dislocation. Such solute-drag reversal has been seen in kinetic Monte Carlo simulations where dislocations moving in a strain field move initially in the direction of nearby impurities [38].

3) The dissolution at high temperature of precipitates decorating the dislocations may unpin the dislocations, allowing the dislocations to move and annihilate. The removal of obstacles pinning dislocations has been previously suggested as a pathway for dislocation recovery based on in-situ TEM observations in metals [39].

The possibility of dislocation motion at phosphorus diffusion temperatures warrants further investigation. It is plausible that this effect is simply an artifact of the etching process caused by the change of dislocation metal decoration. Furthermore, confirmation of dislocation-density reduction rather than merely EPD reduction is needed, perhaps by photoluminescence measurement of dislocation lines. Unfortunately, the dislocation density in these samples exceeded quantifiable limits when measured by synchrotron-based X-ray topography.

\section{CONCLUSION}

Improving lifetime over the entire mc-Si ingot requires an understanding of performance-limiting defects and the development of tailored material-specific defect-engineering approaches. Iron-contaminated materials studied here show strong lifetime improvement with higher gettering temperatures, especially in areas of low dislocation density. Synchrotron-based $\mu$-XRF measurements [9] in samples originating from the same ingot heights as those used here reveal that gettering of precipitated iron improves at these higher temperatures. Coupling higher temperature gettering processes with subsequent lower temperature steps, to avoid degradation because of a highremaining interstitial impurity concentration, captures the benefit of higher temperature processing that dissolves and getters a higher fraction of the precipitated impurity concentration. As an example, we show here that subsequent low-temperature annealing is effective at further improving lifetime. Alternatively, lower temperature P-diffusion following a high-temperature Pdiffusion step produces yet further lifetime benefits, leaving a moderate interstitial iron concentration. Throughput aside, the best performing sample resulted from a sacrificial $920^{\circ} \mathrm{C}$ Pdiffusion targeting impurity-precipitate dissolution, followed by a separate $820^{\circ} \mathrm{C}$ P-diffusion that lowers final impurity pointdefect concentration.

In the most heavily dislocated areas, low lifetimes remain after gettering despite a decrease in the local EPD after P-diffusion at higher temperatures. The reduction in EPD trends monotonically with the P-diffusion temperature, suggesting some interaction with metal gettering, and is most notable in samples with $920^{\circ} \mathrm{C}$ P-diffusion. Confirmation that this EPD reduction is correlated with dislocation density reduction is still required.

To minimize thermal budgets, higher diffusion temperatures should only be applied when necessary, i.e., to regions of material with high concentrations of iron-rich precipitates, and must be verified on the solar cell level. In multicrystalline materials, a reversal in the lifetime contrast between defect-free and defect-rich areas after gettering may be a good indicator of metal-limited material that can be assumed to respond positively to higher gettering temperatures. A process tradeoff can then be determined between improved average lifetime and lifetime variation across the wafer to optimize the cell efficiency distribution.

\section{ACKNOWLEDGMENT}

The authors would like to thank D. Berney Needleman and D. M. Powell for the EPD code support and L. Mahlstaedt for the P-diffusion assistance. 


\section{REFERENCES}

[1] D. Macdonald, A. Cuevas, A. Kinomura, Y. Nakano, and L. J. Geerligs, "Transition-metal profiles in a multicrystalline silicon ingot," J. Appl. Phys., vol. 97, no. 3, pp. 033523-1-033523-7, 2005.

[2] E. R. Weber, "Transition metals in silicon," Appl. Phys. A, Mater. Sci. Process., vol. 30, no. 1, pp. 1-22, 1983.

[3] A. Dastgheib-Shirazi, M. Steyer, G. Micard, H. Wagner, P. P. Altermatt, and G. Hahn, "Relationships between diffusion parameters and phosphorus precipitation during the $\mathrm{POCl}_{3}$ diffusion process," Energy Procedia, vol. 28, pp. 254-262, 2013.

[4] B. Sopori, "Silicon solar-cell processing for minimizing the influence of impurities and defects," J. Electron. Mater., vol. 31, no. 10, pp. 972-980, 2002

[5] D. P. Fenning, J. Hofstetter, M. I. Bertoni, G. Coletti, B. Lai, C. del Cañizo, and T. Buonassisi, "Precipitated iron: A limit on gettering efficacy in multicrystalline silicon," J. Appl. Phys., vol. 113, no. 4, pp. 044521-1044521-12, 2013.

[6] G. Coletti, R. Kvande, V. D. Mihailetchi, L. J. Geerligs, L. Arnberg, and E. J. Øvrelid, "Effect of iron in silicon feedstock on p- and n-type multicrystalline silicon solar cells," J. Appl. Phys., vol. 104, no. 10, pp. 104913-1-104913-11, 2008.

[7] P. S. Plekhanov, R. Gafiteanu, U. M. Gösele, and T. Y. Tan, "Modeling of gettering of precipitated impurities from Si for carrier lifetime improvement in solar cell applications," J. Appl. Phys., vol. 86, no. 5, pp. 24532458, 1999.

[8] D. Macdonald, S. P. Phang, F. E. Rougieux, S. Y. Lim, D. Paterson, D. L. Howard, M. D. de Jonge, and C. G. Ryan, "Iron-rich particles in heavily contaminated multicrystalline silicon wafers and their response to phosphorus gettering," Semicond. Sci. Technol., vol. 27, pp. 125016-1125016-5, 2012.

[9] D. P. Fenning, A. S. Zuschlag, M. I. Bertoni, B. Lai, G. Hahn, and T. Buonassisi, "Improved iron gettering of contaminated multicrystalline silicon by high-temperature phosphorus diffusion," J. Appl. Phys., vol. 113, pp. 214504-1-214504-10, 2013.

[10] C. Ballif, S. Peters, D. Borchert, C. Hässler, J. Isenberg, R. Schindler, W. Warta, and G. Willeke, "Lifetime investigations of degradation effects in processed multicrystalline silicon wafers," in Proc. 17th Eur. Photovoltaic Sol. Energy Conf. Exhib., Munich, Germany, 2001, pp. 1818-1821.

[11] H. J. Möller, T. Kaden, S. Scholz, and S. Würzner, "Improving solar grade silicon by controlling extended defect generation and foreign atom defect interactions," Appl. Phys. A, vol. 96, no. 1, pp. 207-220, 2009.

[12] H. J. Möller, C. Funke, M. Rinio, and S. Scholz, "Multicrystalline silicon for solar cells," Thin Solid Films, vol. 487, no. 1/2, pp. 179-187, 2005.

[13] H. Möller, C. Funke, A. Lawerenz, S. Riedel, and M. Werner, "Oxygen and lattice distortions in multicrystalline silicon," Sol. Energy Mater. Sol. Cells, vol. 72, no. 1, pp. 403-416, 2002.

[14] D. Macdonald and A. Cuevas, "The trade-off between phosphorus gettering and thermal degradation in multicrystalline silicon," in Proc. 16th Eur. Photovoltaic Sol. Energy Conf. Exhib., Glasgow, U.K., Jun. 2000, pp. 1707-1710.

[15] D. Franke, "Rise of dislocation density in crystalline silicon wafers during diffusion processing," in Proc. 3rd World Conf. Photovoltaic Energy Convers., Osaka, Japan, May 2003, pp. 1344-1347.

[16] S. Peters, J. Y. Lee, C. Ballif, D. Borchert, S. W. Glunz, W. Warta, and G. Willeke, "Rapid thermal processing: A comprehensive classification of silicon materials," in Proc. 29th IEEE Photovoltaic Sol. Energy Conf. Exhib., New Orleans, LA, USA, May 2002, pp. 214-217.

[17] S. Riepe, I. E. Reis, W. Kwapil, M. A. Falkenberg, J. Schön, H. Behnken, J. Bauer, D. Kreßner-Kiel, W. Seifert, and W. Koch, "Research on efficiency limiting defects and defect engineering in silicon solar cellsResults of the German research cluster SolarFocus," Phys. Status Solidi (c), vol. 8, no. 3, pp. 733-738, 2011.

[18] T. U. Naerland, L. Arnberg, and A. Holt, "Origin of the low carrier lifetime edge zone in multicrystalline PV silicon," Prog. Photovolt. Res. Appl., vol. 17 , no. 5, pp. 289-296, 2009.

[19] M. C. Schubert, J. Schön, F. Schindler, W. Kwapil, A. Abdollahinia, B. Michl, S. Riepe, C. Schmid, M. Schumann, S. Meyer, and W. Warta, "Impact of impurities from crucible and coating on mc-silicon qualityThe example of iron and cobalt," IEEE J. Photovoltaics, vol. 3, no. 4, pp. 1250-1258, Oct. 2013.
[20] B. L. Sopori, "A new defect etch for polycrystalline silicon," J. Electrochem. Soc., vol. 131, no. 3, pp. 667-672, 1984.

[21] D. B. Needleman, H. Choi, D. M. Powell, and T. Buonassisi, "Rapid dislocation-density mapping of as-cut crystalline silicon wafers," Phys. Status Solidi (RRL), vol. 7, no. 12, pp. 1041-1044, 2013.

[22] K. L. Pollock, J. Junge, and G. Hahn, "Detailed investigation of surface passivation methods for lifetime measurements on p-type silicon wafers," IEEE J. Photovoltaics, vol. 2, no. 1, pp. 1-6, Jan. 2012.

[23] A. Bentzen, B. G. Svensson, E. S. Marstein, and A. Holt, "The influence of structural defects on phosphorus diffusion in multicrystalline silicon," Sol. Energy Mater. Sol. Cells, vol. 90, no. 18/19, pp. 3193-3198, 2006.

[24] O. Schultz, S. W. Glunz, S. Riepe, and G. P. Willeke, "Gettering of multicrystalline silicon for high-efficiency solar cells," in Proc. 21 st Eur. Photovoltaic Sol. Energy Conf. Exhib., Dresden, Germany, 2006, pp. 788-791.

[25] M. Kaes, G. Hahn, A. Metz, G. Agostinelli, Y. Ma, J. Junge, A. Zuschlag, and D. Groetschel, "Progress in high efficiency processing of EFG silicon solar cells," in Proc. 22nd Eur. Photovoltaic Sol. Energy Conf. Exhib., Milan, Italy, 2007, pp. 897-902.

[26] J. Isenberg, J. Dicker, and W. Warta, "Averaging of laterally inhomogeneous lifetimes for one-dimensional modeling of solar cells," J. Appl. Phys., vol. 94, no. 6, pp. 4122-4130, 2003.

[27] B. Michl, M. Rüdiger, J. A. Giesecke, M. Hermle, W. Warta, and M. C. Schubert, "Efficiency limiting bulk recombination in multicrystalline silicon solar cells," Sol. Energy Mater. Sol. Cells, vol. 98, pp. 441447, 2012

[28] H. Wagner, M. Müller, G. Fischer, and P. P. Altermatt, "A simple criterion for predicting multicrystalline $\mathrm{Si}$ solar cell performance from lifetime images of wafers prior to cell production," J. Appl. Phys., vol. 114, no. 5, pp. 054501-1-054501-8, 2013

[29] D. Macdonald, J. Tan, and T. Trupke, "Imaging interstitial iron concentrations in boron-doped crystalline silicon using photoluminescence," $J$. Appl. Phys., vol. 103, no. 7, pp. 073710-1-073710-7, 2008.

[30] S. Herlufsen, J. Schmidt, D. Hinken, K. Bothe, and R. Brendel, "Photoconductance-calibrated photoluminescence lifetime imaging of crystalline silicon," Physica Status Solidi RRL, vol. 2, no. 6, pp. 245247, 2008.

[31] Y.-C. Fan, J. Tan, S. P. Phang, and D. Macdonald, "Iron imaging in multicrystalline silicon wafers via photoluminescence," in Proc. 35th IEEE Photovoltaic Sol. Energy Conf. Exhib., Honolulu, HI, USA, 2010, pp. 439442.

[32] A. Bentzen, A. Holt, R. Kopecek, G. Stokkan, J. S. Christensen, and B. G. Svensson, "Gettering of transition metal impurities during phosphorus emitter diffusion in multicrystalline silicon solar cell processing," $J$. Appl. Phys., vol. 99, no. 9, pp. 093509-1-093509-6, 2006.

[33] A. Bentzen and A. Holt, "Overview of phosphorus diffusion and gettering in multicrystalline silicon," Mater. Sci. Eng. B, vol. 159, pp. 228-234, 2009.

[34] J. Haunschild, M. Glatthaar, M. Demant, J. Nievendick, M. Motzko, S. Rein, and E. R. Weber, "Quality control of as-cut multicrystalline silicon wafers using photoluminescence imaging for solar cell production," Sol. Energy Mater. Sol. Cells, vol. 94, no. 12, pp. 2007-2012, 2010.

[35] T. Buonassisi, M. D. Pickett, A. A. Istratov, E. Sauer, T. C. Lommasson, E. Marstein, T. Pernau, R. F. Clark, S. Narayanan, S. M. Heald, and E. R. Weber, "Interactions between metals and different grain boundary types and their impact on multicrystalline silicon device performance," in Proc. 4th World Conf. Photovoltaic Energy Convers., Waikoloa, HI, USA, May 2006, pp. 944-947.

[36] H. J. Choi, M. I. Bertoni, J. Hofstetter, D. P. Fenning, D. M. Powell, S. Castellanos, and T. Buonassisi, "Dislocation density reduction during impurity gettering in multicrystalline silicon," IEEE J. Photovoltaics, vol. 3, no. 1, pp. 189-198, Jan. 2013.

[37] T. Ervik, M. Kivambe, G. Stokkan, B. Ryningen, and O. Lohne, "High temperature annealing of bent multicrystalline silicon rods," Acta Materialia, vol. 60, no. 19, pp. 6762-6769, 2012.

[38] Y. Wang, D. J. Srolovitz, J. M. Rickman, and R. Lesar, "Dislocation motion in the presence of diffusing solutes: A computer simulation study," Acta Materialia, vol. 48, no. 9, pp. 2163-2175, 2000.

[39] F. Prinz, A. S. Argon, and W. C. Moffatt, "Recovery of dislocation structures in plastically deformed copper and nickel single crystals," Acta Metallurgica, vol. 30, no. 4, pp. 821-830, 1982. 


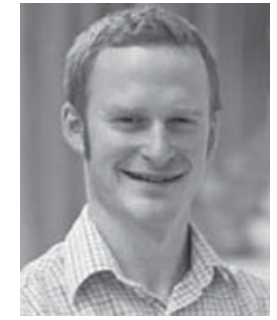

David P. Fenning received the B.S. degree from Stanford University, Stanford, CA, USA, in 2008, and the M.S. and Ph.D. degrees from the Massachusetts Institute of Technology (MIT), Cambridge, MA, USA, in 2010 and 2013, respectively, all in mechanical engineering. His Ph.D. research with the MIT PVLab focused on improving impurity gettering in silicon solar cell materials using defect kinetics simulation and synchrotron-based X-ray characterization.

$\mathrm{He}$ is currently a Postdoctoral Researcher with MITs Electrochemical Energy Laboratory, working to develop efficient, low-cost photoelectrochemical devices for water-splitting and $\mathrm{CO}_{2}$ reduction. $\mathrm{He}$ will join the faculty of the Department of Nanoengineering, University of California at San Diego, in 2015, continuing his research in photovoltaics and energy storage technologies.

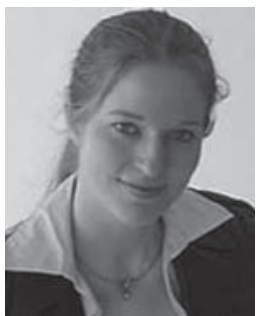

Annika S. Zuschlag was born in Konstanz, Germany, in 1981. She received the Diploma degree in physics from the University of Konstanz, Konstanz, in 2007, where her focus was set on metallic nanostructures and their properties as optical antennas. Since 2007, she has been working toward the $\mathrm{Ph} . \mathrm{D}$. degree with the Photovoltaics Division, Department of Physics, University of Konstanz.

She is currently a coordinator of the German research cluster "SolarWinS." Her research interests include defects in crystalline silicon materials, their impact on material quality, and the influence of solar cell processes on defect properties.

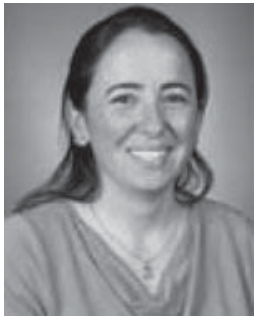

Mariana I. Bertoni received the B.S. and Diploma degrees in chemical engineering from the Buenos Aires Institute of Technology, Buenos Aires, Argentina, and the Ph.D. degree in materials science and engineering from Northwestern University, Evanston, IL, USA.

She was a Postdoctoral Fellow with Creavis Technologies \& Innovation in Germany in 2007 and the Massachusetts Institute of Technology, Cambridge, MA, USA, during 2008-2010. She is currently an Assistant Professor with the School of Electrical Computer and Energy Engineering, Arizona State University, Tempe, AZ, USA. Her research interests include understanding and engineering the defects that govern device performance of photovoltaic materials.

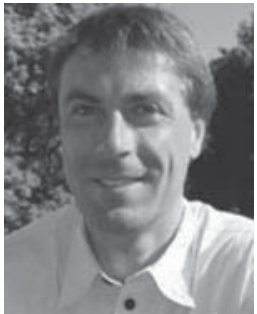

Giso Hahn was born in Frankfurt am Main, Germany, in 1969. He received the Diploma degree in physics from the University of Stuttgart, Stuttgart, Germany, in 1995, and the Ph.D. degree in physics from the University of Konstanz, Konstanz, Germany, in 1999.

Since 2009, he has been an Apl. Professor with the Department of Physics, University of Konstanz. His research interests include crystalline silicon materials and solar cell process development, including characterization of promising low-cost materials for photovoltaic applications and the development of adapted solar cell processes for these and other materials.

Dr. Hahn is a member of the scientific committees of various conference series (e.g., IEEE PVSC, EU PVSEC, and SiliconPV) and workshops. Among other scientific and technological achievements, his group is interested in transferring technologies from the laboratory stage to industry.

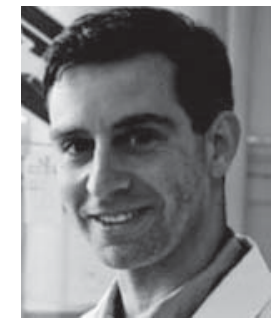

Tonio Buonassisi received the Ph.D. degree in applied science and technology from the University of California at Berkeley, Berkeley, CA, USA, with additional research at the Fraunhofer Institute for Solar Energy Systems and the Max-Planck-Institute for Microstructure Physics.

He is the Head of the Photovoltaic Research Laboratory, Massachusetts Institute of Technology, Cambridge, MA, USA, which combines crystal growth, processing, characterization, defect simulation, and cost-performance modeling to engineer naturally abundant and manufacturable materials into cost-effective, high-performance devices. His research interests include silicon (kerfless absorbers, advanced manufacturing, and defects), Earth-abundant thin films, and high-efficiency concepts.

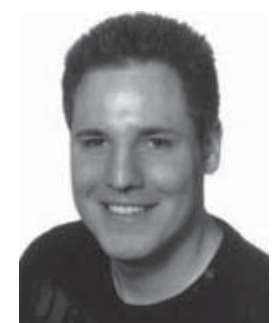

Alexander Frey received the Diploma degree in physics from the University of Konstanz, Konstanz, Germany, in 2011, where his focus was set on the recombination activity of interstitial iron defects in multicrystalline silicon. Since 2012, he has been working toward the Ph.D. degree with the Department of Photovoltaics, University of Konstanz, where he has been developing high-efficient $n$-type silicon solar cells with boron emitters from plasma-enhanced chemical vapor deposition layers. 